\title{
Celiaco Mesenteric Trunk - A Case Report
}

\author{
Dr.Anupama D, Assistant1, Dr.R.Lakshmi Prabha Subhash ${ }^{2}$ \\ ${ }^{12}$ Dept. Of Anatomy, SSMC. Tumkur.Karnataka.India
}

\begin{abstract}
Variations in the branching pattern of abdominal aorta are quite common, knowledge of which is required to avoid complications during surgical interventions involving GIT and posterior abdominal wall. Celiac trunk \& Superior mesenteric Arteries, the ventral aortic branches usually arise independently from Abdominal Aorta, one just above the other. Occasionally they arise from a common aortic origin. This study describes the anomalous origin of these ventral or pre aortic branches of abdominal aorta in the light of embryological and surgical basis. Knowledge of such variations has important clinical significance in abdominal operations like Small and large bowel surgeries, laparoscopic surgery, and radiological procedures in the upper abdomen or invasive arterial procedures.
\end{abstract}

Keywords:Common celiaco mesenteric trunk(CMT), Celiac trunk(CT), Superior mesenteric artery(SMA), Aorta, Aneurysms, Thrombosis, Retro peritoneal procedures.

\section{Introduction}

Development of blood vessels occurs by two mechanisms: Vasculogenesis and Angiogenesis. The Vitelline arteries, initially a number of paired vessels supplying the yolk sac, gradually fuseby the process of angiogenesis and form the arteries in the dorsal wall of mesentery of the gut. In the adult, they are represented by the Pre aortic branches Celiac trunk, Superior Mesenteric artery and Inferior mesenteric artery. ${ }^{1}$ Celiac trunk, the first ventral aortic branch, arises at the level of $12^{\text {th }}$ thorasic vertebra and after a short course divide in to Left gastric, Splenic and Common hepatic arteries. CT was first described by Haller hence its branching pattern is called Tripus Haller. The Common hepatic artery, after its origin runs down to the right along the upper border of $1^{\text {st }}$ part of Duodenum, to give 2 terminal branches, Gastro duodenal and Proper Hepatic arteries. At times it may give off the right Gastric artery before its termination. Gastro duodenal artery, after passing behind the $1^{\text {st }}$ part of Duodenum terminally divides to give Superior Pancreatico duodenal and Right gastro epiploic arteries.The Hepatic artery proper usually gives rise to Rt. Gastric artery and then runs upwards in the right. free margin of lesser omentum in between bile duct and portal vein to divide into right and left Hepatic arteries which supply liver. Thus Celiac trunk supplies Stomach, Liver,Pancreas and a part of Duodenum. ${ }^{2}$

Superior mesenteric artery, the $2^{\text {nd }}$ ventral aortic branch arises at the level of $1^{\text {st }}$ Lumbar vertebra runs downwards and to the left in the root of Mesentery to give Inferior pancreatico duodenal, right colic, Middle colic, Ileocolic, Jejunal and Ileal branches. Thus it supplies a large part of Small intestine and Colon, till the junction of right $2 / 3$ and left $1 / 3$ of Transverse colon. ${ }^{2}$

Thesetwo Pre aortic branches may rarely arise from a common trunk, and it has to be considered with its relation to the surrounding structures as it is a rare gastro intestinal vascular variation and is the the sole source of blood supply to a major segment of GIT. ${ }^{3,45}$ Anatomical variations of the hepatic arteries and celiac trunk are of considerable importance in liver transplants, laparoscopic surgery, radiological abdominal interventions and penetrating injuries to the abdomen. ${ }^{6}$

\section{Case report}

We report a rare variation, a Common Celiaco Mesenteric Trunk(CMT), arising from the abdominal aorta just below the aortic opening which was observed during routine dissection of an 59-year-old Indian male cadaver in the Department of Anatomy, SSMC, Tumkur. The short trunk measuring about $1.3 \mathrm{~cm}$ gave rise to Celiac trunk and Superior mesenteric arteries. Celiac trunk further divided to give Left gastric A, Common hepatic A, Splenic A and a small unnamed artery which joined with another unnamed branch (UN1) from trifurcated Common hepatic artery to form the Gastro duodenal artery. Common hepatc artery, after giving Rt. Gastric artery trifurcated to yield right hepatic, left hepatic and an unnamed branch (ÙN2) which formed Gastro duodenal artery as shown in Fig. 1. Left gastric and Splenic arteries were of large caliber and had shown regular branching pattern. Superior mesenteric artery also shows regular branching pattern. Developmental significance of this variation is discussed with a brief review of literature. 


\section{Dscussion}

Abdominal visceral arteriesarise from the primitive dorsal abdominal aorta through 4 roots.LGA, HA, SA and SMA. These roots are joined together by a longitudinal ventral anastomosis. Normally a cleft forms between the third and fourth roots thus isolating the Celiac trunk from SMA.The CMT is a rare variation $(0.5 \%)$ of the ventral braches of aorta. Usually it is asymptomatic, but at times may present with complications ranging from nonspecific abdominal pain toreal abdominal angina, atherosclerosis, aneurysms and Median arcuate ligament syndrome resulting in complete avascularisation of a large segment of GITand consequent ischemia as this single artery is the sole source of vascularisation of supra colic organs. ${ }^{7}$ Higashi classified anomalies into 4 categories according to the arrangement of the vessels. Type1:Hepatospleno gastric trunk with trifurcation , Type 2:CHA arising from CMT after the splenogastric trunk, Type3:LGA arising from CMT before the hepato splenic trunk.Type4:Separate origins of CHA,SA and LGA from CMT. This kind of vascular variations has to be known to surgeons and radiologists because it may change the management. ${ }^{8}$ Normal Celiac trunks exhibiting trifurcation have been reported with a frequency of $72-90 \%$ in the normal population. ${ }^{6}$ Celiac trunk bifurcation as an anatomical variation has been reported at a rate of about $12 \%$ in the literature.Bergman et al published a metaanalysis of "no Celiac trunk reports" in the literature and calculated the average absence rate of celiac trunk as $0.4 \%$. In another study, celiac trunk was absent in 1 of the 100 cases. Celiac trunk was absent in $1 \%$, a hepatosplenomesenteric trunk was seen in $1 \%$ and a splenomesenteric trunk was present in $1 \%$. Celiac trunk and/or hepatic arterial variation was present in 23 cases $(39.7 \%){ }^{6}$ Eighteen patients (14 men, 4 women), aged between 24 to 77 years, with a Common celiac mesenteric trunk (CMT) were treated between 1965 and 2004 at the University of Michigan. Four patients had CMT aneurysmal or occlusive disease that led to operative treatment ${ }^{7}$. Without knowledge of arterial architecture of the region surgery may lead to considerable errors occasionally leading to lethal complications. A thorough knowledge of the vascular anatomy and variations of the ventral aortic branches is critical to effective interventional treatment of the pathologic conditions related to theCT and SMA which has to be supplemented with Careful interpretation of the angiographic findings of the same if needed. MDCT angiography permits an accurate and detailed analysis of splanchnic vascular anatomy and is required to determine treatment options and to prevent complications arising from vascular variations during surgery or intervention can easily be obtained using MDCT. ${ }^{9}$

\section{References:}

[1]. Vascular development in Cardio vascular System. In Langman's Medical Embryology. T.W. Saddler.11 th ed .p185-89.

[2]. Warwick R, Williams LP.Gray's Anatomy.Susan Standring et al.Elsivier Churchill Livingstone. 39 $9^{\text {th }}$ ed 2005;p.1118-1120.

[3]. Ronald A Bergman.et al.Illustrated encyclopedia of anatomical variations:Opus11:Cardio vascular system:Arteries:Abdomen

[4]. Shuang-Qin Yi, Hayato Terayama, Munekazu Naito et al Common celiacomesenteric trunk, and a brief review of the literature.http://dx.doi.org/10.1016/j.anat.2006.11.013.

[5]. Mehmet Tugrul Yilmaz, Murat Tezer, Aynur Emine Cicekcibasi, Anil Didem Aydin et al.A case report of Celiaco mesenteric trunk.Bio medical research 2013;24(1):150-152.

[6]. M S Ugurel, MD, ${ }^{1} \mathrm{~B}$ Battal, MD,${ }^{2} \mathrm{U}$ Bozlar, MD, ${ }^{1} \mathrm{M}$ S Nural, MD,${ }^{3} \mathrm{M}$ Tasar, MD,${ }^{1} \mathrm{~F}$ Ors, MD, ${ }^{1} \mathrm{M}$ Saglam, MD, ${ }^{1}$ and I Karademir, MD Br J Radiol. 2010 August; 83(992): 661-667.

[7]. Ailawadi G, Cowles RA, Stanley JC, Eliason JL, Williams DM, Colletti LM, Henke PK, Upchurch GR JrCommon celiacomesenteric trunk: aneurysmal and occlusive disease. J Vasc Surg. 2004 Nov;40(5):1040-3

[8]. Nicolas Lagoutte, Olivier Facy, Boris Giiu.Celiacomesenteric trunk: a variation that must be known before aortic surgery.Clinics and Practice 2011; vol1:e69

[9]. Federico Lovisetto , Gianbattista Finocchiaro De Lorenzi, Piera Stancampiano et al .Thrombosis of Celiaco mesenteric trunk:Report of a case .World J Gastroenterol 2012 August 7;18(29):3917-3920

Fig .1 Showing Celiaco mesenteric Trunk( CMT) giving origin to Celiac trunk (CT) and Superior mesenteric artery(SMA) with Splenic artery (SA),Common hepatic artery(CHA), Left gastric artery (LGA), Unnamed branch from CT(UN1) and Unnamed branch from CHA (UN2) and Gastro duodenal

$\operatorname{artery}($ GDA).

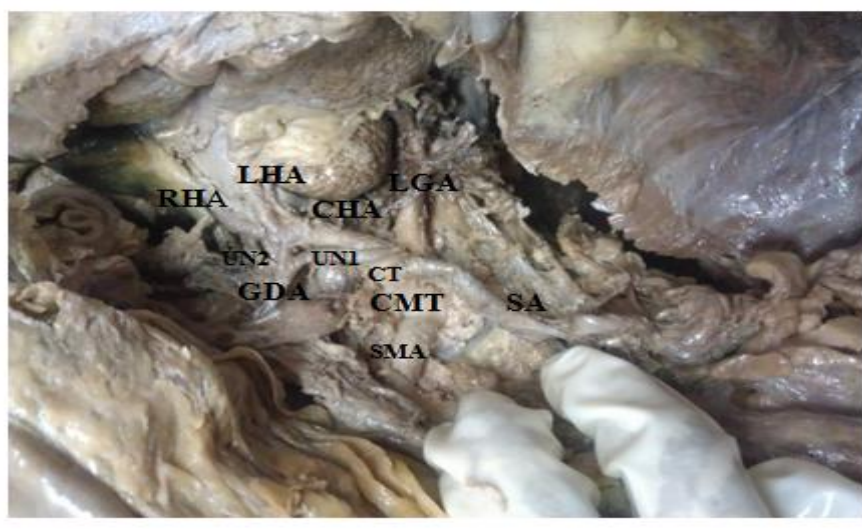

